\title{
Postcesarean wound infection: prevalence, impact, prevention, and management challenges
}

\author{
This article was published in the following Dove Press journal: \\ International Journal of Women's Health \\ 17 February 2017 \\ Number of times this article has been viewed
}

\author{
Sivan Zuarez-Easton' \\ Noah Zafran ${ }^{1,2}$ \\ Gali Garmi ${ }^{1,2}$ \\ Raed Salim ${ }^{1,2}$ \\ 'Department of Obstetrics and \\ Gynecology, Emek Medical Center, \\ Afula, ${ }^{2}$ Rappaport Faculty of \\ Medicine, Technion-Israel Institute \\ of Technology, Haifa, Israel
}

\begin{abstract}
Surgical site infection (SSI) is one of the most common complications following cesarean section, and has an incidence of 3\%-15\%. It places physical and emotional burdens on the mother herself and a significant financial burden on the health care system. Moreover, SSI is associated with a maternal mortality rate of up to $3 \%$. With the global increase in cesarean section rate, it is expected that the occurrence of SSI will increase in parallel, hence its clinical significance. Given its substantial implications, recognizing the consequences and developing strategies to diagnose, prevent, and treat SSI are essential for reducing postcesarean morbidity and mortality. Optimization of maternal comorbidities, appropriate antibiotic prophylaxis, and evidence-based surgical techniques are some of the practices proven to be effective in reducing the incidence of SSI. In this review, we describe the biological mechanism of SSI and risk factors for its occurrence and summarize recent key clinical trials investigating preoperative, intraoperative, and postoperative practices to reduce SSI incidence. It is prudent that the surgical team who perform cesarean sections be familiar with these practices and apply them as needed to minimize maternal morbidity and mortality related to SSI.
\end{abstract}

Keywords: cesarean section, management, surgical site infection

\section{Introduction}

Cesarean delivery is a major obstetrical surgical procedure aiming to save the lives of mothers and fetuses. ${ }^{1}$ The incidence of cesarean deliveries, both repeat and primary, has risen dramatically over the last few decades, with an estimated global number of 22.9 million cesarean deliveries in 2012.,3 As a surgical procedure, cesarean delivery may be accompanied by a number of complications, surgical site infection (SSI) being one of them. The rate of SSI ranges from 3\% to $15 \%$ worldwide. ${ }^{46}$ The variation in incidence may reflect differences in population characteristics and risk factors, perioperative practices, and the duration from the procedure until ascertainment. The risk for developing SSI has significantly decreased in the last three decades, mainly owing to improvements in hygiene conditions, antibiotic prophylaxis, sterile procedures, and other practices. ${ }^{7,8}$ Despite this decrease, the occurrence of SSI is expected to increase given the continuous rise in the incidence of cesarean deliveries. Postcesarean SSI may increase maternal morbidity and mortality. ${ }^{9,10}$ In addition, SSI can be frustrating for the mother trying to recover from the procedure and at the same time take care of the newborn. It may prolong maternal hospitalization, increase health care costs, and lead to other socioeconomic implications. ${ }^{9}$

\section{Methods}

An attempt was made to identify all relevant articles that reported the prevalence, impact, prevention, and management of postcesarean wound infection. The following cc) and incorporate the Creative Commons Attribution - Non Commercial (unported, v3.0) License (http://creativecommons.org/licenses/by-nc/3.0/). By accessing the work you hereby accept the Terms. Non-commercial uses of the work are permitted without any further permission from Dove Medical Press Limited, provided the work is properly attributed. For permission for commercial use of this work, please see paragraphs 4.2 and 5 of our Terms (https://www.dovepress.com/terms.php). 
electronic databases were searched from inception through June 2016: MEDLINE, PubMed, Ovid, and the Cochrane Library. The MeSH headings used included combinations of the terms ["cesarean section" OR "cesarean delivery" OR "cesarean"] AND ["infection" OR "surgical site" OR "antibiotic", OR "skin", OR “wound”, OR “endometritis", OR “abscess", OR "fasciitis", OR "bacteria"] in the title or abstract. All reference lists from relevant articles were searched for additional eligible studies. Randomized trials, cohort, case-control, review, and meta-analysis were eligible. Excluded were comments, letters to the editor, personal communications, and case reports. The search was limited to publications in English only. Two authors (SZE and RS) selected articles first through focused review of abstracts. Eligible studies underwent full-text review. Disagreements between authors over the inclusion and exclusion of studies were resolved by consensus through discussion between the authors.

\section{Definition and microbiology}

The Centers for Disease Control and Prevention defines SSI as an infection occurring within 30 days from the operative procedure in the part of the body where the surgery took place. ${ }^{11}$ It divides SSIs into incisional SSI and organ/space SSI. Incisional SSI is further divided into superficial, involving the skin and subcutaneous tissue, and deep SSI, involving fascial and muscle layers. ${ }^{11}$

Staphylococcus aureus is the most common organism isolated in SSI, accounting for $15 \%-20 \%$ of cases. Gramnegative bacilli, coagulase negative staphylococci, Enterococcus species, and Escherichia coli are other organisms commonly isolated from SSIs. ${ }^{12}$ SSI in relation to cesarean delivery has a distinctive microbial source of pathogens composed of both skin and vaginal origin. ${ }^{13}$ Accordingly, it is usually a polymicrobial infection consisting of both aerobic bacteria and anaerobic organisms. ${ }^{14-16}$ Knowledge of the pathogens and risk factors associated with SSI is essential for developing targeted prevention strategies to reduce the risk and treat the infection.

\section{Risk factors}

Several risk factors for developing postcesarean section SSI are noted in the literature. Identification of these factors is vital for creating targeted practices for reducing SSI rate. Risk factors can be divided into three categories: 1) hostrelated factors, 2) pregnancy and intrapartum-related factors, and 3 ) procedure-related factors. ${ }^{17}$ Host-related risk factors include maternal older or younger age, obesity, residence in rural (compared to urban) area, pregestational diabetes mellitus, previous cesarean delivery, recurrent pregnancy loss, and maternal preoperative condition (American Society of Anesthesiologists score $>3$ ). Pregnancy-related factors reported were hypertensive disorder, gestational diabetes mellitus, twin pregnancy, preterm rupture of membranes, greater number of vaginal examinations, prolonged trial of labor prior to surgery, epidural use, use of internal fetal monitoring, and chorioamnionitis. In regard to the procedure itself, SSI was more common among cesarean sections performed in an emergency setting, nonuse of prophylactic antibiotics, and in cases accompanied by uterine rupture, cesarean hysterectomy, need for blood transfusion and in surgeries of longer duration..$^{5,8,9,18-22}$ Surgery duration of more than 1 hour had been reported to increase the risk for SSI more than twofold. ${ }^{21-23}$

It should be noted that not all studies evaluated SSI separately, and it is often incorporated in a composite outcome including other infectious and noninfectious morbidities (such as wound breakdown).

\section{Prevention strategies}

Many clinical trials explored the implication of various intervention strategies to reduce SSI rate following cesarean section. Recognizing risk factors, particularly those that are modifiable, proper perioperative preparation, and use of distinct surgical techniques have been reported to affect the rate of SSI. ${ }^{24}$ The practices used to reduce SSI rate can be divided into three categories according to the time of intervention: preoperative, intraoperative, and postoperative practices.

\section{Preoperative practices \\ Management of comorbidities}

Diabetes mellitus is a well-known comorbidity associated with postoperative wound complications. Poorly controlled diabetes impairs host immune response and delays reepithelialization of wounds. ${ }^{25}$ For diabetic women, perioperative glycemic control may be essential for preventing SSI. ${ }^{26}$

\section{Hair removal}

There is no adequate literature to rely on regarding hair removal techniques before cesarean section, and the recommendations are extrapolated from other types of surgery. A Cochrane review published in 2012 suggested that hair removal at the time of surgery was not associated with lower postoperative SSI rates and that it should be done only to facilitate surgery or for applying adhesive dressings. ${ }^{27}$ 
Shaving the surgical site has been shown to be associated with significantly higher rates of SSI compared to clipping, as a result of microscopic breaks in the skin caused by the razor. ${ }^{27}$

\section{Skin preparation}

The skin is a main source of pathogens causing SSI. Preoperative skin preparation with antiseptic agents has been proven to reduce the risk of SSI. ${ }^{28}$ There is no consensus regarding what type of skin preparation may be most efficient for the prevention of postcesarean SSI. ${ }^{29,30}$ Two large randomized controlled trials (RCTs) assessed this issue. Ngai et al ${ }^{31}$ compared chlorhexidine with alcohol, povidone-iodine with alcohol, and the sequential combination of both solutions for preventing SSI postcesarean section. Their study included 1,404 women undergoing nonemergent cesarean section. The three skin preparation groups had similar SSI rates $(3.9 \%-4.6 \%)$, leading to the conclusion that no particular method of skin preparation before cesarean section is recommended. However, Tuuli et $\mathrm{al}^{32}$ evaluated the use of chlorhexidine with alcohol compared to povidone-iodine with alcohol for skin antisepsis in 1,147 women undergoing cesarean section. The use of chlorhexidine-alcohol resulted in a significantly lower risk of overall SSI (4.0\%) after cesarean section compared to iodine-alcohol (7.3\%) ( $P=0.02$; relative risk [RR]: $0.55 ; 95 \%$ confidence interval [CI]: 0.34-0.9). The incidence of adverse skin reactions was similar in both groups.

\section{Vaginal preparation}

This intervention has been evaluated in two systematic reviews. Dahlke et $\mathrm{al}^{33}$ reported no difference in the incidence of wound infection when adding vaginal preparation to the standard abdominal preparation in cesarean section. In a Cochrane review, vaginal preparation with povidone-iodine solution before cesarean section reduced the risk of postcesarean endometritis from $7.2 \%$ to $3.6 \%$ (RR: $0.39,95 \% \mathrm{CI}$ : 0.16-0.97), particularly in women with ruptured membranes (from $15.4 \%$ to $1.4 \%$; RR: 0.13; 95\% CI: 0.02-0.66). ${ }^{34}$ There was no difference regarding wound infection and postoperative fever.

\section{Antibiotic prophylaxis}

A significant component that affects the rate of SSI is the use of antibiotic prophylaxis in cesarean section. Three Cochrane reviews evaluated the role of antibiotic prophylaxis in cesarean section. When comparing antibiotic prophylaxis to no prophylaxis or placebo for preventing infection following cesarean section, the use of prophylactic antibiotics significantly reduced the incidence of wound infection (RR: 0.40, 95\% CI: 0.35-0.46), endometritis (RR: $0.38,95 \%$ CI: 0.34-0.42), and maternal serious infectious complications (RR: 0.31, 95\% CI: 0.20-0.49). ${ }^{35}$ The benefit was noticed in both elective and nonelective cesarean sections. Cephalosporins and penicillins were found to have similar efficacy at cesarean section in preventing immediate postoperative infections, including wound infection. ${ }^{36}$ In terms of timing of prophylactic antibiotic administration, women who received antibiotics preoperatively had a lower composite infectious morbidity compared to women who received antibiotics after cord clamping (RR: 0.57, 95\% CI: $0.45-0.72) .{ }^{37}$ This result was specifically due to reduction in endometritis (RR: $0.54,95 \% \mathrm{CI}: 0.36-0.79)$ and wound infection (RR: 0.59, 95\% CI: 0.44-0.81). There were no significant differences in adverse neonatal outcomes. When assessing antibiotics doses, single-dose therapy was as efficacious as multiple doses in most studies. ${ }^{38-40}$ After a single $1 \mathrm{~g}$ intravenous dose of cefazolin, a therapeutic level is maintained for approximately $3-4$ hours. A higher dose may be indicated for obese women with body mass index $>30 \mathrm{~kg} / \mathrm{m}^{2}$ or weight $>100 \mathrm{~kg} .{ }^{41}$ Several recent studies comparing preoperative $2 \mathrm{~g}$ with $3 \mathrm{~g}$ cefazolin in morbidly obese gravid women before cesarean section found no difference in the rate of SSI or in the adipose tissue antibiotic concentration between the two regimens. ${ }^{42-44}$ One trial did find higher adipose concentrations of cefazolin after administration of $3 \mathrm{~g}$ but did not evaluate the effect on SSI occurrence. ${ }^{45}$ The American College of Obstetricians and Gynecologists, in its committee opinion, recommends antimicrobial prophylaxis for all cesarean deliveries unless the patient is already receiving an antibiotic regimen with appropriate coverage (eg, for chorioamnionitis). The antibiotics should be administered within 60 minutes before the procedure. A single dose of a targeted antibiotic, such as a first-generation cephalosporin, is the first-line antibiotic of choice, unless significant drug allergies are present. In obese women (body mass index $>30 \mathrm{~kg} / \mathrm{m}^{2}$ ), a higher dose of preoperative antibiotics prophylaxis should be considered. Repeated doses are reserved for particular situations, as in the case of major intraoperative bleeding. ${ }^{46}$

\section{Intraoperative practices}

\section{Surgical personnel}

Staff education programs and refresher courses in aseptic and scrub techniques have been shown to reduce the incidence of SSI in elective and nonelective cesarean deliveries. ${ }^{47,48}$ 


\section{Perioperative oxygen supplementation}

Several RCTs evaluated the use of high $(80 \%)$ perioperative oxygen supplementation concentrations versus low $(30 \%)$ on the incidence of SSI. ${ }^{49-51}$ None of the trials found a significant difference, concluding that increasing the concentration of oxygen in women undergoing cesarean deliveries does not decrease the rate of SSI.

\section{Surgical techniques}

\section{Skin incision type}

A Cochrane review published in 2013 included two studies comparing the Joel-Cohen incision with the Pfannenstiel incision. ${ }^{52}$ Overall, there was a $65 \%$ reduction in postoperative febrile morbidity (RR: 0.35 ; 95\% CI: $0.14-0.87$; $P=0.023$ ) with the Joel-Cohen incision. Only one study noted the incidence of wound infection separately and found no difference between the two techniques. ${ }^{53}$ In regard to muscle cutting, one study compared the Maylard muscle-cutting incision with the Pfannenstiel incision and reported no difference in febrile morbidity (RR: 1.26 ; $95 \%$ CI: $0.08-19.50$, $P=0.87$ ) or wound infection (RR: 1.26 ; 95\% CI: 0.27-5.91; $P=0.77) .^{54}$

The CORONIS trial, ${ }^{55}$ a multicenter, unmasked RCT conducted at 19 institutions, assessed the effect of five elements of the cesarean section technique on maternal and neonatal outcomes. Blunt versus sharp abdominal entry was one of the five elements that were examined. The findings did not show significant differences between the groups regarding febrile morbidity, endometritis, or wound infection.

\section{Expansion of uterine incision}

Five studies were included in the Cochrane review that compared blunt versus sharp dissection when performing the uterine incision. ${ }^{56}$ There was no significant difference in febrile morbidity following blunt or sharp extension of the uterine incision. The mean blood loss $(-55.00 \mathrm{~mL} ; 95 \%$ CI: -79.48 to $-30.52 ; P=0.00001)$ and the need for blood transfusion (RR: $0.24 ; 95 \%$ CI: $0.09-0.62 ; P=0.0035$ ) were significantly lower following blunt extension. ${ }^{56} \mathrm{~A}$ metaanalysis evaluating the same interventions found that blunt expansion was associated with fewer unintended extensions and favorable maternal outcomes with no difference in the rate of endometritis compared to sharp dissection. ${ }^{57}$ Another meta-analysis that compared cephalad-caudad versus transverse blunt expansion of the low transverse uterine incision during cesarean delivery found that the cephalad-caudad direction was associated with lower risks of postpartum blood loss, unintended extension, uterine vessels injury, and use of additional stitches. The effect on wound infection was not addressed. ${ }^{58}$

\section{Placental removal}

Spontaneous placental delivery with gentle cord traction compared to manual removal of the placenta was examined in a Cochrane review in 2010. ${ }^{59}$ Manual removal of the placenta was associated with more endometritis (RR: $1.64 ; 95 \% \mathrm{CI}$ : $1.42-1.90 ; P<0.00001)$ and more blood loss $(94.42 \mathrm{~mL} ; 95 \%$ CI: $17.19-171.64 ; P=0.017)$. The review did not evaluate the effect of placental delivery on wound infection. One study reported the effect of the two placental delivery techniques on wound infection and found no difference between the two techniques. ${ }^{60}$

\section{Uterine exteriorization}

Extra-abdominal compared to intra-abdominal repair of the uterine incision was evaluated in the CORONIS study and in a large meta-analysis. ${ }^{55,61}$ Both found no significant differences in complication rates, including endometritis and wound infection, between the two techniques and concluded that both options are acceptable.

\section{Cervical dilatation}

Two reviews evaluated the effect of mechanical cervical dilatation during cesarean section on infectious morbidity. Both found that mechanical cervical dilatation did not affect postcesarean infectious morbidity (including wound infection and endometritis). ${ }^{62,63}$

\section{Closure of the uterine incision}

Single layer uterine closure versus double layer was examined in two large RCTs and a Cochrane review. ${ }^{55,56,64}$ There was no difference in postoperative febrile morbidity, wound infection, and endometritis between the two techniques.

\section{Peritoneal closure}

A Cochrane review and two recent large RCTs found no significant difference in the incidence of postoperative endometritis or wound infection in cases with peritoneal closure compared to nonclosure during cesarean section. ${ }^{55,64,65}$

\section{Intra-abdominal saline irrigation}

The use of intra-abdominal irrigation before abdominal closure was evaluated in a recent meta-analysis that included three RCTs. ${ }^{66}$ Intraoperative saline irrigation was associated with increased intraoperative and postoperative nausea and increased the use of antiemetics without a significant 
reduction in infectious morbidity including postpartum endometritis and wound infection.

\section{Subcutaneous tissue closure}

According to a Cochrane review, closure of the subcutaneous tissue reduced wound composite morbidity including hematoma, seroma, wound infection, and wound separation (RR: $0.68 ; 95 \%$ CI: $0.52-0.88 ; P=0.0039$ ). There was no difference in the risk of wound infection alone or other shortterm outcomes. ${ }^{67}$ In regard to subcutaneous thickness, if depth is $<2 \mathrm{~cm}$, there is no difference in wound disruption between closure and nonclosure. ${ }^{29}$ In women with subcutaneous thickness $>2 \mathrm{~cm}$, closure was associated with a significant decrease in wound complications (RR: 0.66 ; 95\% CI: 0.48-0.91) and is recommended ${ }^{29}$ The use of subcutaneous drainage, regardless of tissue thickness, was not associated with decreased wound morbidity including wound infection. ${ }^{33,68}$

\section{Skin closure}

The two most studied methods for skin closure after cesarean section are staples and subcutaneous sutures. A Cochrane review of eight trials concluded that wound complications and cosmetic outcome are similar between the two techniques. ${ }^{69}$ In contrast, a large meta-analysis concluded that staples closure is associated with twofold increase in wound infection and separation compared with subcuticular sutures. ${ }^{70} \mathrm{~A}$ multicenter RCT found a significant (57\%) decrease in the incidence of wound complications, including wound infection, with suture closure of the skin at cesarean delivery compared with staples $(4.9 \%$ compared to $10.6 \%$; odds ratio [OR]: $0.43 ; 95 \%$ CI: $0.23-0.78) .{ }^{71}$ In particular, wound separation of the skin was significantly decreased from $7.4 \%$ to $1.6 \%$ in women whose incisions were closed with sutures compared with those closed with staples (OR: 0.2; 95\% CI: $0.07-0.51)$. The study was not powered to assess a difference in wound infection alone. A recent meta-analysis reported a lower incidence of wound separations in those closed with suture compared to staples, with no significant differences in infection rate morbidity. ${ }^{72}$

\section{Wound dressing}

There are several types of bandages available for dressing the surgical wound at the end of a surgery. A meta-analysis of 16 trials found no difference in SSI rate between surgical wounds covered with different types of dressings and those left uncovered. ${ }^{73}$ Two Cochrane reviews regarding early $(<48$ hours) versus delayed dressing removal and postoperative bathing reported limited data, but no significant difference in SSI rate was shown. ${ }^{74,75}$ Early (6 hours) compared to delayed (24-48 hours) removal of the wound dressing was also recently examined in a RCT. The authors reported comparable wound complications that included infection, disruption, and seroma/hematoma formation. More women were pleased and satisfied with early removal. ${ }^{76}$

Negative pressure wound therapy is the application of suction to healing wounds. The technique is used for the treatment of chronic wounds. Its use on surgical wounds was evaluated in a meta-analysis by Webster et al, ${ }^{77}$ which did not find it superior to the traditional dressings in terms of wound complications. There are no available RCTs on its role in cesarean section.

\section{Postoperative assessment}

Daily inspection of the cesarean incision is an essential part of the postoperative evaluation. The presence of fever, tenderness, erythema, purulent discharge, or induration should raise a suspicion of infection. ${ }^{78}$ Most wound infections do not become clinically apparent until postoperative days 4-7, when most women have already been discharged from the hospital. ${ }^{78}$ For that reason, it is essential to instruct these women on signs and symptoms requiring further evaluation since early treatment has an important role in preventing severe consequences. ${ }^{26}$

\section{Management}

The management of postcesarean wound infection includes antibiotic treatment, wound exploration, and debridement as soon as indicated. ${ }^{26}$

When there are signs of pelvic infection, empirical broadspectrum antibiotic regimen should be initiated, including anaerobic coverage. An acceptable regimen includes clindamycin with an aminoglycoside or aztreonam. For the coverage of Enterococcus, ampicillin may be added to the regimen. ${ }^{26,79}$ Approximately $90 \%$ of women will be afebrile within 48-72 hours after initiation of antibiotic treatment. Once the women are afebrile and asymptomatic for 24 hours, parenteral antibiotics may be discontinued. If the infection improves with intravenous antibiotics, there is probably no need to follow the intravenous antibiotics with a course of oral antibiotics. ${ }^{80}$

In cases of wound infection with $S$. aureus (extensive cellulitis), vancomycin should be added to the regimen. ${ }^{79}$ Superficial wound infection without purulent discharge can be treated with antibiotics alone. When there is a purulent discharge or concern for deep SSI, the wound must be explored, drained completely, and irrigated. A strict and 
cautious inspection of the fascia is indicated. If it is disrupted but not infected (ie, without necrotizing fasciitis), reapproximation is needed. Otherwise, the wound should be irrigated two to three times a day and allowed to heal by secondary intention. Antibiotics should be continued until all signs of infection are resolved. ${ }^{79}$

An uncommon but severe complication of wound infection is necrotizing fasciitis. It is a fast-expanding gangrenous infection involving the skin, subcutaneous tissue, and the fascia. ${ }^{79}$ The incidence of necrotizing fasciitis according to Goepfert et al ${ }^{81}$ is 1.8 per 1,000 cesarean deliveries, and the mean time to diagnosis was 10 days from the procedure. Necrotizing fasciitis is most likely to occur among immunocompromised patients. The pathogen is usually polymicrobial with Clostridium and Group A Streptococcus. The presence of crepitation on physical examination or the presence of gas in the subcutaneous tissue on imaging tests can assist in the diagnosis. ${ }^{26}$ Necrotizing fasciitis is a life-threatening condition with reported mortality of up to $50 \%$. Early aggressive medical and surgical treatment is the mainstay of management, which includes the combination of broad-spectrum antibiotics with extensive debridement of necrotic tissue. ${ }^{26}$

\section{Conclusion}

Cesarean delivery is one of the most frequent surgical interventions performed worldwide and accounts for up to $60 \%$ of deliveries in a number of countries. ${ }^{82,83}$ It carries risk for various short-term postoperative morbidities including SSI. In addition, infection occurring after delivery may lead to substantial physical and emotional burdens on the mother and to a significant financial burden on the health care system. ${ }^{84}$ Likewise, postcesarean infection is a major contributor to maternal death related directly to pregnancy. Review of maternal death in the UK over a period of 3 years (2006-2008) revealed that the incidence of maternal death directly related to pregnancy decreased from 6.24 to 4.67 per 100,000 maternities compared to the period between 2003 and 2005 ( $P=0.02)$. In spite of this decline, there has been an increase in maternal death related to genital tract sepsis, mainly from community-acquired Group A streptococcal disease, and sepsis was found to be the leading cause of direct maternal death. ${ }^{85}$

Given its substantial implications, recognizing the consequences and building strategies to prevent and treat SSI are essential for reducing postcesarean maternal morbidity and mortality. To begin with, decreasing or at least controlling the continuous rise in cesarean section rate worldwide is essential in reducing the occurrence of SSI related to the procedure. There are multiple factors that contributed to the increase in cesarean section rate worldwide. However, discussing and presenting recent evidence regarding this essential issue is beyond the scope of this review. In addition, recognizing risk factors, particularly modifiable ones that may be related to the woman, pregnancy, or to the technique itself and implementing strategies to prevent, diagnose, and treat infection in time are all vital steps for reducing the occurrence of SSI and its consequences. Medical staff responsible for the procedure should be familiar with aspects of the procedure that have been evaluated in good clinical trials to minimize maternal and perinatal morbidity and mortality.

\section{Disclosure}

The authors report no conflicts of interest in this work.

\section{References}

1. Charoenboon C, Srisupundit K, Tongsong T. Rise in cesarean section rate over a 20-year period in a public sector hospital in northern Thailand. Arch Gynecol Obstet. 2013;287(1):47-52.

2. Miller ES, Hahn K, Grobman WA. Consequences of a primary elective cesarean delivery across the reproductive life. Obstet Gynecol. 2013; 121(4):789-797.

3. Molina G, Weiser TG, Lipsitz SR, et al. Relationship between cesarean delivery rate and maternal and neonatal mortality. JAMA. 2015;314(21): 2263-2270.

4. Olsen MA, Butler AM, Willers DM, Devkota P, Gross GA, Fraser VJ. Risk factors for surgical site infection after low transverse cesarean section. Infect Control Hosp Epidemiol. 2008;29(6):477-484; discussion 485-486.

5. Schneid-Kofman N, Sheiner E, Levy A, Holcberg G. Risk factors for wound infection following cesarean deliveries. Int J Gynecol Obstet. 2005;90(1):10-15.

6. Opøien HK, Valbø A, Grinde-Andersen A, Walberg M. Post-cesarean surgical site infections according to CDC standards: rates and risk factors. A prospective cohort study. Acta Obstet Gynecol Scand. 2007; 86(9):1097-1102.

7. Gibbs RS. Clinical risk factors for puerperal infection. Obstet Gynecol. 1980;55(Suppl 5):S178-S184.

8. Krieger Y, Walfisch A, Sheiner E. Surgical site infection following cesarean deliveries: trends and risk factors. J Matern Fetal Neonatal Med. 2016;705:1-5.

9. Salim R, Braverman M, Teitler N, Berkovic I, Suliman A, Shalev E. Risk factors for infection following cesarean delivery: an interventional study. J Matern Neonatal Med. 2012;25(12):2708-2712.

10. Awad SS. Adherence to surgical care improvement project measures and post-operative surgical site infections. Surg Infect (Larchmt). 2012;13(4):234-237.

11. Horan TC, Gaynes RP, Martone WJ, Jarvis WR. CDC definitions of nosocomial surgical site infections, 1992: a modification of CDC definitions of surgical wound infections. Infect Control Hosp Epidemiol. 1992; 13(10):606-608.

12. Korol E, Johnston K, Waser N, et al. A systematic review of risk factors associated with surgical site infections among surgical patients. PLoS One. 2013;8(12):e83743.

13. Gur R, Duggal SD, Rongpharpi SR, et al. Post caesarean surgical site infections. Arch Clin Microbiol. 2015;6(1):1-6.

14. Gilstrap LC, Cunningham FG. The bacterial pathogenesis of infection following cesarean section. Obstet Gynecol. 1979;53(5):545-549. 
15. Watts DH, Eschenbach DA, Kenny GE. Early postpartum endometritis: the role of bacteria, genital mycoplasmas, and Chlamydia trachomatis. Obstet Gynecol. 1989;73(1):52-60.

16. Newton ER, Wallace PA. Effects of prophylactic antibiotics on endometrial flora in women with postcesarean endometritis. Obstet Gynecol. 1998;92(2):262-268

17. Rubin RH. Surgical wound infection: epidemiology, pathogenesis, diagnosis and management. BMC Infect Dis. 2006;6:171.

18. Mitt P, Lang K, Peri A, Maimets M. Surgical-site infections following cesarean section in an Estonian university hospital: postdischarge surveillance and analysis of risk factors. Infect Control Hosp Epidemiol. 2005;26(5):449-454.

19. Wloch C, Wilson J, Lamagni T, Harrington P, Charlett A, Sheridan E. Risk factors for surgical site infection following caesarean section in England: results from a multicentre cohort study. BJOG. 2012;119(11): 1324-1333.

20. Beattie PG, Rings TR, Hunter MF, Lake Y. Risk factors for wound infection following caesarean section. Aust N Z J Obstet Gynaecol. 1994; 34(4):398-402.

21. Killian CA, Graffunder EM, Vinciguerra TJ, Venezia RA. Risk factors for surgical-site infections following cesarean section. Infect Control Hosp Epidemiol. 2001;22(10):613-617.

22. Tran TS, Jamulitrat S, Chongsuvivatwong V, Geater A. Risk factors for postcesarean surgical site infection. Obstet Gynecol. 2000;95(3): 367-371.

23. Suonio S, Saarikoski S, Vohlonen I, Kauhanen O. Risk factors for fever, endometritis and wound infection after abdominal delivery. Int J Gynecol Obstet. 1989;29(2):135-142.

24. McKibben RA, Pitts SI, Suarez-Cuervo C, Perl TM, Bass EB. Practices to reduce surgical site infections among women undergoing cesarean section: a review. Infect Control Hosp Epidemiol. 2015;36(8): 915-921.

25. Takoudes TC, Weitzen S, Slocum J, Malee M. Risk of cesarean wound complications in diabetic gestations. Am J Obstet Gynecol. 2004; 191(3):958-963.

26. Fitzwater JL, Tita AT. Prevention and management of cesarean wound infection. Obstet Gynecol Clin North Am. 2014;41(4):671-689.

27. Tanner J, Norrie P, Melen K. Preoperative hair removal to reduce surgical site infection. Cochrane Database Syst Rev. 2011;(11): CD004122.

28. Mangram AJ, Horan TC, Pearson ML, Silver LC, Jarvis WR. Guideline for prevention of surgical site infection. Am J Infect Control. 1999; 27(2):97-134

29. Berghella V, Baxter JK, Chauhan SP. Evidence-based surgery for cesarean delivery. Am J Obstet Gynecol. 2005;193(5):1607-1617.

30. Hadiati DR, Hakimi M, Nurdiati DS, Ota E. Skin preparation for preventing infection following caesarean section. Cochrane Database Syst Rev. 2014;(9):CD007462.

31. Ngai IM, Arsdale A Van, Govindappagari S, et al. Skin preparation for prevention of surgical site infection after cesarean delivery a randomized controlled trial. Obstet Gynecol. 2015;126(6):1251-1257.

32. Tuuli MG, Liu J, Stout MJ, et al. A randomized trial comparing skin antiseptic agents at cesarean delivery. $N$ Engl J Med. 2016;374(7): 647-655.

33. Dahlke JD, Mendez-Figueroa H, Rouse DJ, Berghella V, Baxter JK, Chauhan SP. Evidence-based surgery for cesarean delivery: an updated systematic review. Am J Obstet Gynecol. 2013;209(4): 294-306.

34. Haas DM, Morgan S, Contreras K. Vaginal preparation with antiseptic solution before cesarean section for preventing postoperative infections. Cochrane Database Syst Rev. 2014;9:CD007892.

35. Smaill FM, Grivell RM. Antibiotic prophylaxis versus no prophylaxis for preventing infection after cesarean section. Cochrane Database Syst Rev. 2014;(10):CD007482.

36. Gyte GML, Dou L, Vazquez JC. Different classes of antibiotics given to women routinely for preventing infection at caesarean section. Cochrane Database Syst Rev. 2014;(11):CD008726.
37. Mackeen AD, Packard RE, Ota E, Berghella V, Baxter JK. Timing of intravenous prophylactic antibiotics for preventing postpartum infectious morbidity in women undergoing cesarean delivery. Cochrane Database Syst Rev. 2014;12:CD009516.

38. Gonik B. Single- versus three-dose cefotaxime prophylaxis for cesarean section. Obstet Gynecol. 1985;65(2):189-193.

39. Saltzman DH, Eron LJ, Tuomala RE, Protomastro LJ, Sites JG. Singledose antibiotic prophylaxis in high-risk patients undergoing cesarean section. A comparative trial. J Reprod Med. 1986;31(8):709-712.

40. Roex AJ, Puyenbroek JI, van Loenen AC, Arts NF. Single- versus threedose cefoxitin prophylaxis in caesarean section: a randomized clinical trial. Eur J Obstet Gynecol Reprod Biol. 1987;25(4):293-298.

41. Pai MP, Bearden DT. Antimicrobial dosing considerations in obese adult patients. Pharmacotherapy. 2007;27(8):1081-1091.

42. Ahmadzia HK, Patel EM, Joshi D, et al. Obstetric surgical site infections: 2 grams compared with 3 grams of cefazolin in morbidly obese women. Obstet Gynecol. 2015;126(4):708-715.

43. Maggio L, Nicolau DP, Dacosta M, Rouse DJ, Hughes BL. Cefazolin prophylaxis in obese women undergoing cesarean delivery. Obstet Gynecol. 2015;125(5):1205-1210.

44. Young OM, Shaik IH, Twedt R, et al. Pharmacokinetics of cefazolin prophylaxis in obese gravidae at time of cesarean delivery. Am J Obstet Gynecol. 2015;213(4):541.e1-e7.

45. Swank ML, Wing DA, Nicolau DP, McNulty JA. Increased 3-gram cefazolin dosing for cesarean delivery prophylaxis in obese women. Am J Obstet Gynecol. 2015;213(3):415.e1-e8.

46. ACOG. Practice Bulletin No. 120: use of prophylactic antibiotics in labor and delivery. Obstet Gynecol. 2011;117(6):1472-1483.

47. Salim R, Braverman M, Berkovic I, Suliman A, Teitler N, Shalev E. Effect of interventions in reducing the rate of infection after cesarean delivery. Am J Infect Control. 2011;39(10):e73-e78.

48. Rauk PN. Educational intervention, revised instrument sterilization methods, and comprehensive preoperative skin preparation protocol reduce cesarean section surgical site infections. Am J Infect Control. 2010;38(4):319-323.

49. Williams NL, Glover MM, Crisp C, Acton AL, McKenna DS. Randomized controlled trial of the effect of $30 \%$ versus $80 \%$ fraction of inspired oxygen on cesarean delivery surgical site infection. Am J Perinatol. 2013 ; 30(9):781-786.

50. Gardella C, Goltra LB, Laschansky E, et al. High-concentration supplemental perioperative oxygen to reduce the incidence of postcesarean surgical site infection: a randomized controlled trial. Obstet Gynecol. 2008;112(3):545-552.

51. Duggal N, Poddatorri V, Noroozkhani S, Siddik-Ahmad RI, Caughey AB. Perioperative oxygen supplementation and surgical site infection after cesarean delivery. Obstet Gynecol. 2013;122(1):79-84.

52. Mathai M, Hofmeyr GJ, Mathai NE. Abdominal surgical incisions for caesarean section. Cochrane Database Syst Rev. 2013;(5):CD004453.

53. Franchi M, Ghezzi F, Raio L, et al. Joel-Cohen or Pfannenstiel incision at cesarean delivery: does it make a difference? Acta Obstet Gynecol Scand. 2002;81:1040-1046.

54. Giacalone PL, Daures JP, Vignal J, Herisson C, Hedon B, Laffargue F. Pfannenstiel versus Maylard incision for cesarean delivery: a randomized controlled trial. Obstet Gynecol. 2002;99(5):745-750.

55. Abalos E, Addo V, Brocklehurst $P$, et al. Caesarean section surgical techniques (CORONIS): a fractional, factorial, unmasked, randomised controlled trial. Lancet. 2013;382(9888):234-248.

56. Dodd JM, Anderson ER, Gates S, Grivell RM. Surgical techniques for uterine incision and uterine closure at the time of caesarean section. Cochrane Database Syst Rev. 2014;(7):CD004732.

57. Saad AF, Rahman M, Costantine MM, Saade GR. Blunt versus sharp uterine incision expansion during low transverse cesarean delivery: a metaanalysis. Am J Obstet Gynecol. 2014;211(6):684.e1-e11.

58. Xodo S, Saccone G, Cromi A, Ozcan P, Spagnolo E, Berghella V. Cephalad-caudad versus transverse blunt expansion of the low transverse uterine incision during cesarean delivery. Eur J Obstet Gynecol Reprod Biol. 2016;202:75-80. 
59. Anorlu RI, Maholwana B, Hofmeyr GJ. Methods of delivering the placenta at caesarean section. Cochrane Database Syst Rev. 2010;(3): CD004737.

60. Lasley DS, Eblen A, Yancey MK, Duff P. The effect of placental removal method on the incidence of postcesarean infections. Am J Obstet Gynecol. 1997;176(6):1250-1254.

61. Walsh CA, Walsh SR. Extraabdominal vs intraabdominal uterine repair at cesarean delivery: a metaanalysis. Am J Obstet Gynecol. 2009; 200(6):625.e1-e8.

62. Liabsuetrakul T, Peeyananjarassri K. Mechanical dilatation of the cervix at non-labour caesarean section for reducing postoperative morbidity. Cochrane Database Syst Rev. 2011;(11):CD008019.

63. Tosun M, Sakinci M, Çelik H, et al. A randomized controlled study investigating the necessity of routine cervical dilatation during elective cesarean section. Arch Gynecol Obstet. 2011;284(1):85-89.

64. Brocklehurst P. Caesarean section surgical techniques: a randomised factorial trial (CAESAR). BJOG. 2010;117(11):1366-1376.

65. Bamigboye AA, Hofmeyr GJ. Closure versus non-closure of the peritoneum at caesarean section. Cochrane Database Syst Rev. 2003;(8): CD000163.

66. Eke AC, Shukr GH, Chaalan TT, Nashif SK, Eleje GU. Intra-abdominal saline irrigation at cesarean section: a systematic review and metaanalysis. J Matern Fetal Neonatal Med. 2016;29(10):1588-1594.

67. Anderson ER, Gates S. Techniques and materials for closure of the abdominal wall in caesarean section. Cochrane Database Syst Rev. 2004; (4):CD004663.

68. Hellums EK, Lin MG, Ramsey PS. Prophylactic subcutaneous drainage for prevention of wound complications after cesarean delivery-a metaanalysis. Am J Obstet Gynecol. 2007;197(3):229-235.

69. Mackeen AD, Berghella V, Larsen ML. Techniques and materials for skin closure in caesarean section. Cochrane Database Syst Rev. 2012; (9):CD003577.

70. Tuuli MG, Rampersad RM, Carbone JF, Stamilio D, Macones GA, Odibo AO. Staples compared with subcuticular suture for skin closure after cesarean delivery: a systematic review and meta-analysis. Obstet Gynecol. 2011;117(3):682-690.

71. Mackeen AD, Khalifeh A, Fleisher J, et al. Suture compared with staple skin closure after cesarean delivery. Obstet Gynecol. 2014; 123(6):1169-1175.

72. MacKeen AD, Schuster M, Berghella V. Suture versus staples for skin closure after cesarean: a metaanalysis. Am J Obstet Gynecol. 2015; 212(5):621.e1-e10.
73. Walter CJ, Dumville JC, Sharp CA, Page T. Systematic review and metaanalysis of wound dressings in the prevention of surgical-site infections in surgical wounds healing by primary intention. Br J Surg. 2012;99(9): 1185-1194.

74. Toon CD, Sinha S, Davidson BR, Gurusamy KS. Early versus delayed post-operative bathing or showering to prevent wound complications. Cochrane Database Syst Rev. 2015;(7):CD010075.

75. Toon CD, Lusuku C, Ramamoorthy R, Davidson BR, Gurusamy KS. Early versus delayed dressing removal after primary closure of clean and clean-contaminated surgical wounds. Cochrane Database Syst Rev. 2015; (9):CD010259.

76. Peleg D, Eberstark E, Warsof SL, Cohen N, Ben Shachar I. Early wound dressing removal after scheduled cesarean delivery: a randomized controlled trial. Am J Obstet Gynecol. 2016;215(3):388.e1-e5.

77. Webster J, Scuffham P, Stankiewicz M, Chaboyer WP. Negative pressure wound therapy for skin grafts and surgical wounds healing by primary intention. Cochrane Database Syst Rev. 2014;(10):CD009261.

78. Owen J, Andrews WW. Wound complications after cesarean sections. Clin Obstet Gynecol. 1994;37(4):842-855.

79. Duff P. Maternal and perinatal infection-bacterial. In: Gabbe SG, Niebyl JR, Simpson JL, et al, editors. Obstetrics Normal and Problem Pregnancies. 6th ed. Philadelphia, PA: Elsevier Inc.; 2012:1140-1155.

80. Mackeen AD, Packard RE, Ota E, Speer L. Antibiotic regimens for postpartum endometritis. Cochrane Database Syst Rev. 2015;(2): CD001067.

81. Goepfert AR, Guinn DA, Andrews WW, Hauth JC. Necrotizing fasciitis after cesarean delivery. Obstet Gynecol. 1997;89(3):409-412.

82. Gibbons L, Belizán JM, Lauer JA, Betrán AP, Merialdi M, Althabe F. The global numbers and costs of additionally needed and unnecessary caesarean sections performed per year: overuse as a barrier to universal coverage. World Health Rep. 2010;30:1-31.

83. Belizan JM, Althabe F, Barros FC, Alexander S. Rates and implications of caesarean sections in Latin America: ecological study. BMJ. 1999; 319(7222):1397-1400.

84. Olsen MA, Butler AM, Willers DM, Gross GA, Hamilton BH, Fraser VJ. Attributable costs of surgical site infection and endometritis after low transverse cesarean delivery. Infect Control Hosp Epidemiol. 2010; 31(3):276-282.

85. Centre for Maternal and Child Enquiries (CMACE). Saving mothers' lives: reviewing maternal death to make motherhood safer: 2006-2008. The eighth report on confidential enquiries into maternal deaths in the United Kingdom. BJOG. 2011;118(Suppl 1):s1-s203.
International Journal of Women's Health

\section{Publish your work in this journal}

The International Journal of Women's Health is an international, peerreviewed open-access journal publishing original research, reports, editorials, reviews and commentaries on all aspects of women's healthcare including gynecology, obstetrics, and breast cancer. The manuscript management system is completely online and includes

\section{Dovepress}

a very quick and fair peer-review system, which is all easy to use Visit http://www.dovepress.com/testimonials.php to read real quotes from published authors. 